Hydrol. Earth Syst. Sci., 17, 2209-2217, 2013

www.hydrol-earth-syst-sci.net/17/2209/2013/

doi:10.5194/hess-17-2209-2013

(c) Author(s) 2013. CC Attribution 3.0 License.

\title{
Climate-vegetation-soil interactions and long-term hydrologic partitioning: signatures of catchment co-evolution
}

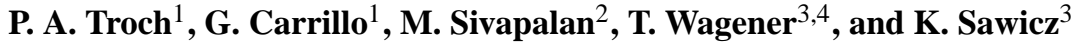 \\ ${ }^{1}$ University of Arizona, Tucson, USA \\ ${ }^{2}$ University of Illinois at Urbana-Champaign, Illinois, USA \\ ${ }^{3}$ Pennsylvania State University, State College, Pennsylvania, USA \\ ${ }^{4}$ University of Bristol, Bristol, UK
}

Correspondence to: P. A. Troch (patroch@hwr.arizona.edu)

Received: 6 February 2013 - Published in Hydrol. Earth Syst. Sci. Discuss.: 7 March 2013

Revised: 11 May 2013 - Accepted: 14 May 2013 - Published: 18 June 2013

\begin{abstract}
Budyko (1974) postulated that long-term catchment water balance is controlled to first order by the available water and energy. This leads to the interesting question of how do landscape characteristics (soils, geology, vegetation) and climate properties (precipitation, potential evaporation, number of wet and dry days) interact at the catchment scale to produce such a simple and predictable outcome of hydrological partitioning? Here we use a physically-based hydrologic model separately parameterized in 12 US catchments across a climate gradient to decouple the impact of climate and landscape properties to gain insight into the role of climate-vegetation-soil interactions in long-term hydrologic partitioning. The 12 catchment models (with different paramterizations) are subjected to the 12 different climate forcings, resulting in $14410 \mathrm{yr}$ model simulations. The results are analyzed per catchment (one catchment model subjected to 12 climates) and per climate (one climate filtered by 12 different model parameterization), and compared to water balance predictions based on Budyko's hypothesis $\left(E / P=\varphi\left(E_{\mathrm{p}} / P\right)\right.$; $E$ : evaporation, $P$ : precipitation, $E_{\mathrm{p}}$ : potential evaporation). We find significant anti-correlation between average deviations of the evaporation index $(E / P)$ computed per catchment vs. per climate, compared to that predicted by Budyko. Catchments that on average produce more $E / P$ have developed in climates that on average produce less $E / P$, when compared to Budyko's prediction. Water and energy seasonality could not explain these observations, confirming previous results reported by Potter et al. (2005). Next, we analyze which model (i.e., landscape filter) characteristics explain the catchment's tendency to produce more or less $E / P$.
\end{abstract}

We find that the time scale that controls subsurface storage release explains the observed trend. This time scale combines several geomorphologic and hydraulic soil properties. Catchments with relatively longer subsurface storage release time scales produce significantly more $E / P$. Vegetation in these catchments have longer access to this additional groundwater source and thus are less prone to water stress. Further analysis reveals that climates that give rise to more (less) $E / P$ are associated with catchments that have vegetation with less (more) efficient water use parameters. In particular, the climates with tendency to produce more $E / P$ have catchments that have lower $\%$ root fraction and less light use efficiency. Our results suggest that their exists strong interactions between climate, vegetation and soil properties that lead to specific hydrologic partitioning at the catchment scale. This co-evolution of catchment vegetation and soils with climate needs to be further explored to improve our capabilities to predict hydrologic partitioning in ungauged basins.

\section{Introduction}

Catchment hydrologic partitioning, regional vegetation composition and soil properties are strongly affected by climate (Budyko, 1974; Whittaker and Niering, 1964; Jenny, 1941), but the effect of climate-vegetation-soil interactions on river basin water balance is still poorly understood. Wolock and McCabe (1999) determined the hydrologic concepts needed in a water balance model to estimate the spatial variation in mean annual runoff for the 344 climate divisions in the 
conterminous United States. The results of their study indicate that almost all of the information required for explaining the spatial variation of mean annual runoff is contained in mean annual precipitation and potential evaporation. However, they required estimates of soil moisture storage capacity and seasonality in water supply to accurately estimate the magnitude of mean annual runoff (Milly, 1994). Potter et al. (2005) reached contradictory conclusions after studying the mean annual water balance of 262 catchments around Australia. They found that estimates of mean annual runoff from a model that accounts for seasonality and a priori estimates of catchment-scale soil moisture capacity compared poorly with observations. Further analysis showed that calibrated values of soil moisture storage capacity (to reproduce observations) for summer-dominant rainfall catchments were significantly lower than the a priori estimates, suggesting that in these catchments infiltration-excess runoff is an important process that was not accounted for in the original model.

These and many other studies indicate that Budyko's hypothesis (i.e., that mean annual evaporation is uniquely governed by the ratio of mean annual potential evaporation (climatic water demand) and mean annual precipitation (climatic water supply), the aridity index $E_{\mathrm{p}} / P$ ) is valid across many climates and physiographic settings. Based on a large number of precipitation and runoff data from catchments across the world, Budyko (1974) suggested that the average annual water balance at catchment scales is governed by the following empirical relationship:

$\frac{E}{P}=\left[\frac{E_{\mathrm{p}}}{P} \tanh \left(\frac{P}{E_{\mathrm{p}}}\right)\right]\left[1-e^{-\left(E_{\mathrm{p}} / P\right)}\right]^{0.5}$

Budyko's observation leads to the interesting question of how do landscape characteristics (soils, geology, vegetation) and climate properties (precipitation, potential evaporation, number of wet and dry days) interact at the catchment scale to produce such a simple and predictable outcome of hydrological partitioning? Recently, Gentine et al. (2012) addressed this question by determining vegetation parameter values in a simple stochastic water balance model that includes infiltration-excess overland flow to reproduce Budyko's hypothesis across 460 catchments around the conterminous US. They found that aboveground transpiration efficiency and belowground rooting structure adapt to the aridity index and the climate seasonality. In Mediterranean climates, where water supply and demand are out of phase, plants develop deeper roots to take advantage of larger storage capacity of water in soils to survive long dry spells (Gerrits et al., 2009).

The study of Gentine et al. (2012) suggests that vegetation adapts to local climate conditions in ways that optimize water use efficiency. This supports the findings of Huxman et al. (2004) and Troch et al. (2009) where similar water use efficiency strategies were hypothesized based on whole biome and catchment response, respectively. The strategies that vegetation adopts may be different in different climatic and geologic settings: deep rooting strategies in Western Australia with a strong Mediterranean climate (Silberstein et al., 2001), and over-storey-under-storey dynamics in Darwin, Northern Australia, with a tropical climate (Schymanski et al., 2008).

In this study, we test Budyko's hypothesis that available water and energy are the main controls on hydrologic partitioning. If this hypothesis holds true than moving climates across different catchments should result in predictable hydrologic partitioning in accordance with Budyko's curve. We test this hypothesis by means of a process-based hydrologic model applied in 12 US catchments across a climate gradient. We use the 12 model parameterizations to decouple climate and landscape properties to gain insight into the role of climate-vegetation-soil interactions in long-term hydrologic partitioning. Carrillo et al. (2011) present the results of applying our hydrologic model to these 12 catchments, and demonstrate that the resulting model parameterizations are capable of capturing the hydrologic response across the climate gradient at different temporal scales, from decades to daily. These 12 behavioral catchment models are subjected to the 12 different climate forcings, resulting in $14410 \mathrm{yr}$ model simulations. The results are analyzed per catchment (one catchment model subjected to 12 climates) and per climate (one climate filtered by 12 different model parameterization), and compared to water balance predictions based on Budyko's hypothesis. The methodology adopted here is similar in many respects to the diagnostic analyses presented by Jothityangkoon and Sivapalan (2009) to decipher differences of inter-annual variability of annual water balance between several catchments in Australia and New Zealand. In Sect. 2, we give a brief overview of the model being used, together with some basic information regarding the 12 catchments selected from the MOPEX database. In Sect. 3, we present the results of simulating hydrologic response by means of the 12 behavioral models forced by $10 \mathrm{yr}$ of climate observations. In Sect. 4, we interpret these results in light of model and climate characteristics.

\section{Process-based modeling of hydrologic response across a climate gradient}

\subsection{Hillslope storage Boussinesq-Soil Moisture model (Carrillo et al., 2011)}

We refer to Carrillo et al. (2011) for a detailed description of the process-based model used in this study. The model is based on the semi-distributed hillslope-storage Boussinesq (hsB) model, developed by Troch et al. (2003). hsB allows for the parsimonious simulation of shallow perched aquifer dynamics at the hillslope spatial scale. This hillslope subsurface flow model is coupled with a land surface water and energy balance model to account for root zone soil moisture dynamics and how it affects infiltration, percolation, evaporation, transpiration and recharge to the shallow hsB aquifer. Rainfall interception by vegetation canopy is parameterized 
by means of time-variable leaf area index information derived from remote-sensing observations. A simple temperature based snow accumulation and melt model completes the land surface components of the model. A fraction of total recharge is assumed to contribute to a deep aquifer through fractured bedrock flow features.

The model parameters are informed from meteorological and hydrological observations selected to represent the different dynamic components in the model. For instance, baseflow dynamics during the dormant season are synthesized in the baseflow recession master curve, which allows selecting aquifer parameters that accurately represent these observed dynamics. Likewise, vegetation parameters are selected from observations during the growing season when the processes represented by these model parameters are likely dominating the catchment hydrologic response. Through this manual calibration strategy guided by physical understanding, we obtain 12 behavioral model parameterization for each selected catchment across a climate gradient (Fig. 1).

\subsection{Data}

The study catchments were selected from the MOPEX database and represent a range of different climates, from semi-arid to humid (Duan et al., 2006). The inset of Fig. 1 illustrates that the average water balance of these 12 catchments follows Budyko's hypothesis quite closely, despite the heterogeneity in climate, topography, soils and vegetation. Some catchments have seasonal snow cover, but in none of these catchments snowmelt is the dominant runoff generation process. We refer to Carrillo et al. (2011) for a complete list of catchment characteristics and model parameters for these catchments.

\subsection{Model validation}

Each of 12 catchment model parameterization was calibrated using $5 \mathrm{yr}$ of climate forcing at the daily time step and validated using all $10 \mathrm{yr}$ of the decade. From the simulated response, we computed long-term water balance variables, such as runoff coefficient and baseflow index, as well as streamflow regime curves using monthly data and flow duration curves using daily data. Performance indicators such as the Nash-Suttclife efficiency and mean absolute error were used to confirm the capacity of each model to simulate streamflow response across time scales. More information is reported in Carrillo et al. (2011).

\section{Decoupling climate and landscape properties}

\subsection{Testing Budyko's hypothesis}

Using the 12 behavioral models we can decouple the effect of climate and landscape properties on hydrologic response. We focus on long-term hydrologic partitioning so that we can

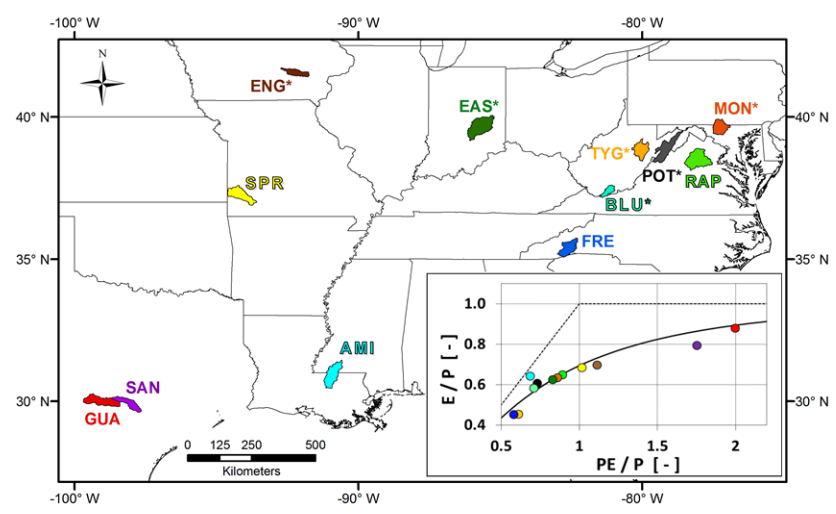

Fig. 1. Study sites location. Snow catchments are indicated with an *. Inset: Evaporation Index $(E / P)$ vs. Aridity Index $\left(E_{\mathrm{p}} / P\right)$, continuous black curve corresponds to Eq. (1).

investigate what causes Budyko's hypothesis to hold across so many climates and landscapes. In the following, we will illustrate our methodology using data and simulations from Spring River, Missouri.

Figure 2 shows model simulation results when varying climates filtered by the model representing the hydrologic response of Spring River (top panel), and when varying filters using the climate of Spring River (bottom panel). The solid line indicates Budyko's hypothesis (Eq. 1) and the different symbols show deviations from the solid line when different climates are filtered by one model (top) and when different models are used to filter one climate (bottom). For each simulation (in this case $2 \times 12$ ) we compute the difference between the simulated hydrologic partitioning and Budyko's hypothesis, indicated by $\Delta(E / P)$ (a positive $\Delta(E / P)$ means that Budyko's hypothesis has less evaporation than simulated). The Spring River catchment in Missouri shows that when the 12 climatic forcings are applied to its model parameterization, a mean positive $\Delta(E / P)$ results. This indicates that independent of climate (wet and cold vs. hot and dry), this filter always generates less runoff than estimated using Budyko's hypothesis. On the other hand, when this catchment's climate is filtered by 12 different catchment model parameterizations, a mean negative $\Delta(E / P)$ is observed, suggesting that independent of filter this climate typically generates less evaporation as compared to Budyko's prediction.

Figure 3 summarizes the results of the above-described methodology for all 144 simulations. The rows in Fig. 3 give results per catchment (one catchment's model filtering 12 different climates), whereas the columns give results per climate (one catchment's climate being filtered by 12 different models). Figure 4 displays the average deviations of the individual hydrologic partitioning with respect to Budyko's hypothesis (the $\Delta(E / P)$ values illustrated in Fig. 2) when analyzed per climate (x-axis) and per catchment (y-axis). The data suggests that a linear relationship between these values is statistically significant at $p<0.05$ and explains $45 \%$ 

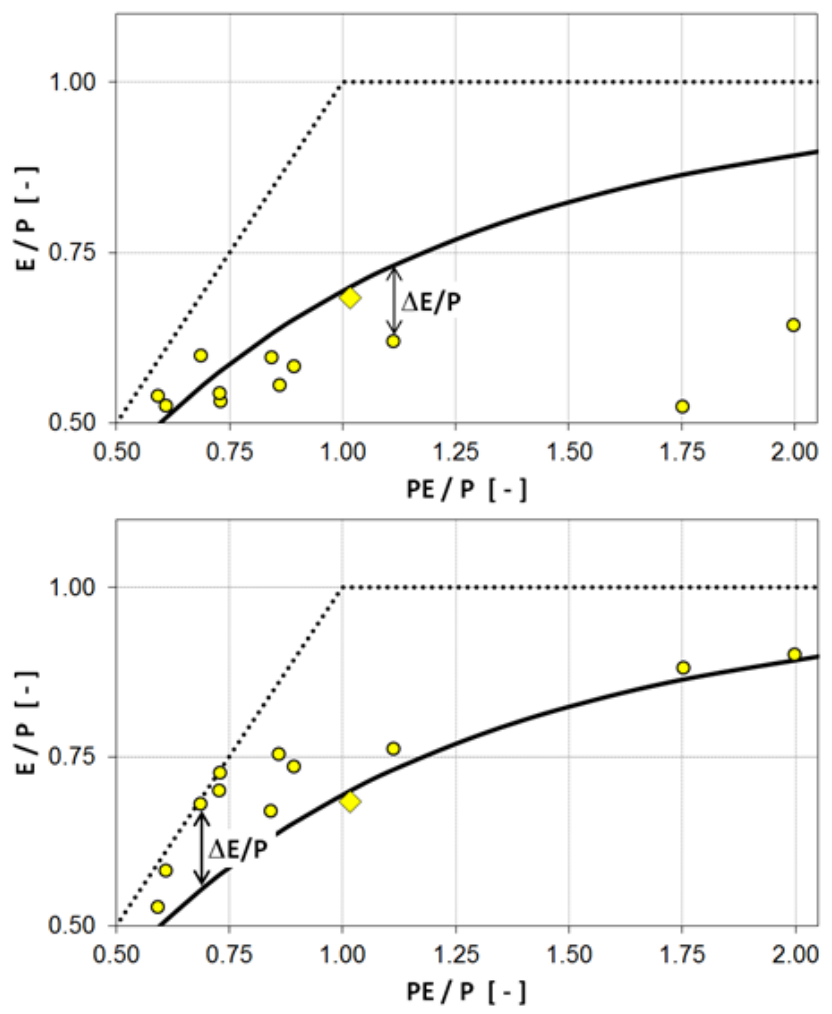

Fig. 2. Illustration of $\Delta E / P$ calculation. Markers correspond to the evaporation index $(E / P)$ vs. Aridity Index $\left(E_{\mathrm{p}} / P\right)$ for Spring River, Missouri. Continuous black line represents Eq. (1). Diamond shaped marker corresponds to the Spring River catchment with its own climate. Top: results for the Spring River climate filtered by 12 catchments; bottom: results for the Spring River catchment under 12 climates.

of the observed variability. There is an anti-correlation between persistent deviations from the Budyko's hypothesis per catchment and its corresponding climate. For instance, for Spring River the catchment's model parameterization seems to produce, on average, more evaporation, while it's corresponding climate seems to produce, on average, less evaporation. We can now examine different climate and landscape properties (directly observed or captured by the models' parameters) to explain this observation. Before we present results of this analysis, we investigate whether climate characteristics alone can explain the observed behavior.

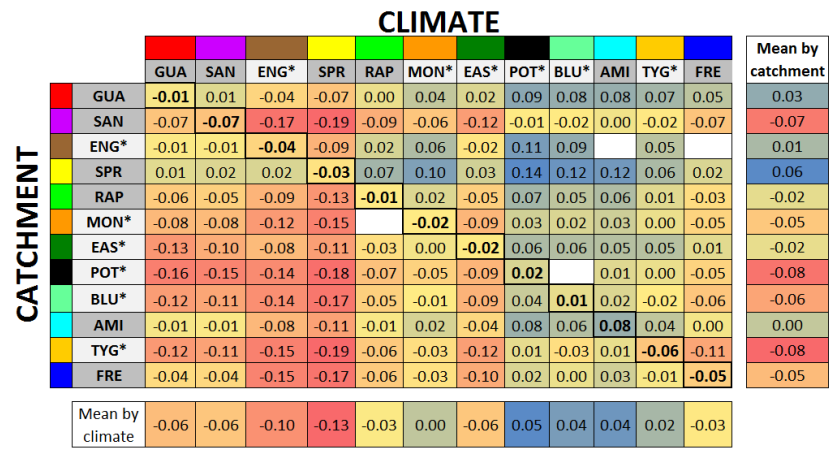

Fig. 3. $\Delta E / P$ values for 12 climates filtered through 12 catchments. Values are averaged by rows (one catchment forced by 12 climates) and by columns (one climate filtered by 12 catchments) - Color scale ranges from red to blue denoting low to high $\Delta E / P$ values, respectively.

\subsection{The effect of intra-annual variability in water and energy availability}

The question arises whether the patterns we see in Fig. 4 are the result of the intra-annual variability of water and energy availability present in the different climates used in this study. When water and energy availability are out of phase one would expect that such climates would always lead to higher runoff amounts, because there is not enough energy to evaporate the rainfall when it becomes available as soil moisture. Vice versa one expects climates with in-phase water and energy availability to generate more evaporation as there is energy available when water is present. In order to test the effect of intra-annual variability on our results, we have computed the seasonality index, SI (Walsh and Lawler, 1981):

$\mathrm{SI}=\frac{1}{P} \sum_{m=1}^{12}\left|X_{m}-\frac{P}{12}\right|$

where $P$ is mean annual precipitation and $X_{m}$ is the mean monthly precipitation. Table 1 provides the values and qualitatively description of SI for the 12 climates. Following Walsh and Lawler's (1981) precipitation regime scale, the maximum level is described as "Extreme seasonality, with almost all precipitation in 1-2 months", and corresponds to SI $>1.20$. Because none of the 12 climates even reached a "Seasonal" classification, corresponding to SI values between 0.60 and 0.79 , an alternative index was devised to quantify seasonality. Using the correlation coefficient between mean monthly precipitation and mean monthly temperature, $R_{P-T}$, the effects of seasonality can be further examined.

In a study to explain spatial variability in mean annual runoff, Wolock and McCabe (1999) calculated $R_{P-T}$ for 344 climate divisions in the conterminous United Sates in order to account for seasonality effects. They clustered $R_{P-T}$ values in five groups, having the most out-of-phase regions 
Table 1. Seasonality index for the 12 MOPEX catchments (* indicates catchment with some snow).

\begin{tabular}{lrl}
\hline Climate & $\begin{array}{r}\text { Seasonality } \\
\text { Index }\end{array}$ & Precipitation Regime \\
\hline GUA & 0.22 & Precipitation spread throughout the year, but with definite wetter season \\
SAN & 0.21 & Precipitation spread throughout the year, but with definite wetter season \\
ENG* & 0.42 & Rather seasonal with short drier season \\
SPR & 0.30 & Precipitation spread throughout the year, but with definite wetter season \\
RAP & 0.13 & Precipitation spread throughout the year \\
MON* $^{*}$ & 0.11 & Precipitation spread throughout the year \\
EAS* & 0.23 & Precipitation spread throughout the year, but with definite wetter season \\
POT $^{*}$ & 0.15 & Precipitation spread throughout the year \\
BLU* $^{*}$ & 0.17 & Precipitation spread throughout the year \\
AMI & 0.17 & Precipitation spread throughout the year \\
TYG $^{*}$ & 0.16 & Precipitation spread throughout the year \\
FRE & 0.15 & Precipitation spread throughout the year \\
\hline
\end{tabular}

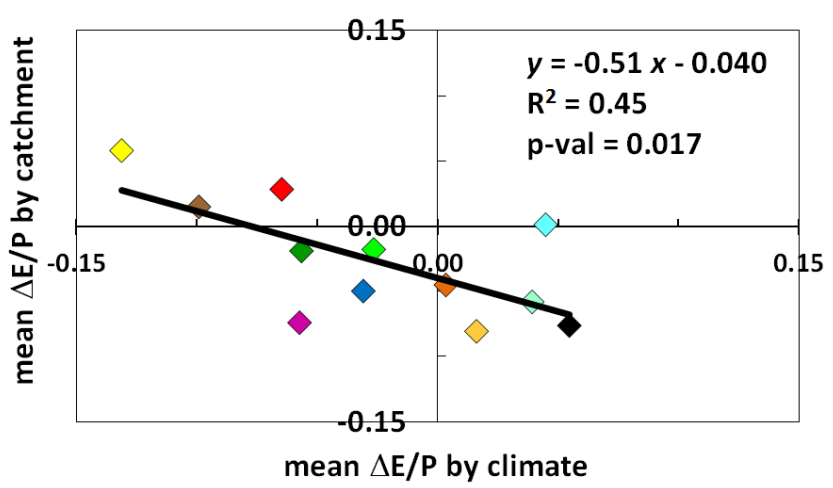

Fig. 4. Correlation between average $\Delta E / P$ evaluated by catchment and by climate (sample size: $12 ; p$ value: 0.02 (this value expresses the probability that the observed trend is due to chance)).

with $R_{P-T}$ values lower than -0.61 , and the most in-phase region with $R_{P-T}$ values higher than +0.61 . Table 2 shows $R_{P-T}$ values, in ascending order, for the 12 catchments in the present study. Even the most negative $R_{P-T}$ value $(-0.49$ for AMI) is still far from the threshold for strong seasonality effects $\left(R_{P-T}<-0.61\right)$. In fact, some $R_{P-T}$ values for the 12 catchments imply an opposite effect on water partitioning when compared to observations. For example, the Amite River climate has positive values for $\Delta E / P$ but it also has the most negative correlation (out-of-phase) between monthly precipitation and temperature. The opposite situation is illustrated with Spring River climate, which has negative values for $\Delta E / P$ but has one of the highest positive $R_{P-T}$ values (in-phase).

Although these results are contradictory, Wolock and McCabe (1999) noted that seasonality effects improve the explanatory power in their models only for climate regions on the west coast $\left(R_{P-T}<0.61\right)$, whereas seasonality has little effect in regions of the country where water supply and demand are in-phase. Our study focuses entirely on catchment east of the Rocky Mountains. Their study also classified re- gions as out-of-phase, where the evaporation index was significantly higher than expected according to Budyko's hypothesis (Fig. 8 in Wolock and McCabe, 1999).

Finally, from the analysis of daily precipitation and temperature time series, two climatic variables were identified that may explain the observed pattern in the mean $\Delta E / P$ values by climate. These variables are: the fraction of rainy days, $F_{\mathrm{RD}}$ (a measure of storminess, see Jothityangkoon and Sivapalan, 2009), and the mean temperature during rainy days, $T_{\mathrm{RD}}$. An empirical model was developed to test the relationship between mean $\Delta E / P$ by climate and these two variables. We consider a linear relationship between the two variables $F_{\mathrm{RD}}$ and $T_{\mathrm{RD}}$ and $\Delta E / P$ by climate:

$$
\Delta(E / P)_{\text {climate }}=-0.7150+0.7707 F_{\mathrm{RD}}+0.0081 T_{\mathrm{RD}}
$$

This model explains $60 \%$ of the variance and is significant at $p<0.05$. It is clear that these two characteristics of the climate will affect the way catchments partition incoming water and energy fluxes and will therefore strongly interact with the different hydrologic processes, such as soil moisture dynamics and vegetation water use efficiency.

\section{Relationships between climate, landscape and model characteristics and hydrologic partitioning}

\subsection{Analysis by catchment}

Figure 5 shows some statistically significant relationships between average deviations from Budyko's hypothesis and observed climate and landscape properties. The top panel suggests a linear relationship between $\Delta(E / P)$ by catchment and mean storm duration of that catchment. The linear regression line explains $50 \%$ of the observed variability. This result can be interpreted as follows: when mean storm duration in a particular catchment increases, the tendency of the catchment's model is to produce more runoff, independent of climate. This suggests that some model parameters have 
Table 2. Linear correlation coefficient between mean monthly precipitation and mean monthly temperature $\left(R_{P-T}\right)$ for the 12 MOPEX catchments.

\begin{tabular}{llr}
\hline Catchment & ID & $R_{P-T}$ \\
\hline Amite, LA & AMI & -0.49 \\
French B., NC & FRE & -0.27 \\
Bluestone, WV & BLU* $^{*}$ & -0.16 \\
Tygart Valley, WV & TYG $^{*}$ & 0.07 \\
San Marcos, TX & SAN & 0.15 \\
Monocay, MD & MON* & 0.17 \\
Rappahanock, VA & RAP & 0.19 \\
South Potomac, WV & POT $^{*}$ & 0.28 \\
Guadalupe, TX & GUA $^{*}$ & 0.32 \\
East Fork, IN & EAS & 0.48 \\
Spring, MO & SPR & 0.61 \\
English, IA & ENG* & 0.91 \\
\hline
\end{tabular}

assumed values that favor runoff production and that this affects runoff generation no matter what the imposed climate on that model. The bottom panel in Fig. 5 shows a linear relationship between $\Delta(E / P)$ by catchment and catchment average slope. Apparently, when the catchment slope is high the catchment's model will generate more runoff, independent of climate. The explained variance of the linear regression through the data points is $45 \%$.

\subsection{Analysis by climate}

Carrillo et al. (2011) defined several model time scales to compare similarities between different catchments (e.g., time scale of root zone filling by rainfall or time scale of root zone emptying by evaporation). We analyzed all of these time scales with respect to average deviations from Budyko's hypotheses per climate, and found that a time scale related to perched aquifer dynamics explains best the observations. Figure 6 compares the $\Delta(E / P)$ by climate and this important model parameter, the perched aquifer advective time scale. This time scale is computed as follows:

$$
\tau=\frac{L f}{2 k_{\mathrm{h}}\left(\sin \alpha-a_{\mathrm{c}} p D \cos \alpha\right)}
$$

where $L[\mathrm{~m}]$ is the average hillslope length, $\alpha$ is the average hillslope slope angle, $f[-]$ is the perched aquifer drainable porosity, $k_{\mathrm{h}}\left[\mathrm{m} \mathrm{day}^{-1}\right]$ is the horizontal hydraulic conductivity of the aquifer, $D[\mathrm{~m}]$ is the aquifer depth, $p[-]$ is a linearization parameter (set to $1 / 3$ in the model), and $a_{\mathrm{c}}[1 / \mathrm{m}]$ is the average hillslope convergence rate (see Carrillo et al., 2011, for more details). This time scale quantifies whether subsurface flow is dominated by advective (low value for $\tau$ ) versus diffusive processes (high value). When flow in the perched aquifer is dominated by diffusion (high values of $\tau)$, the corresponding climate of that catchment generates, on average, more evaporation. When $\tau$ is high, water will
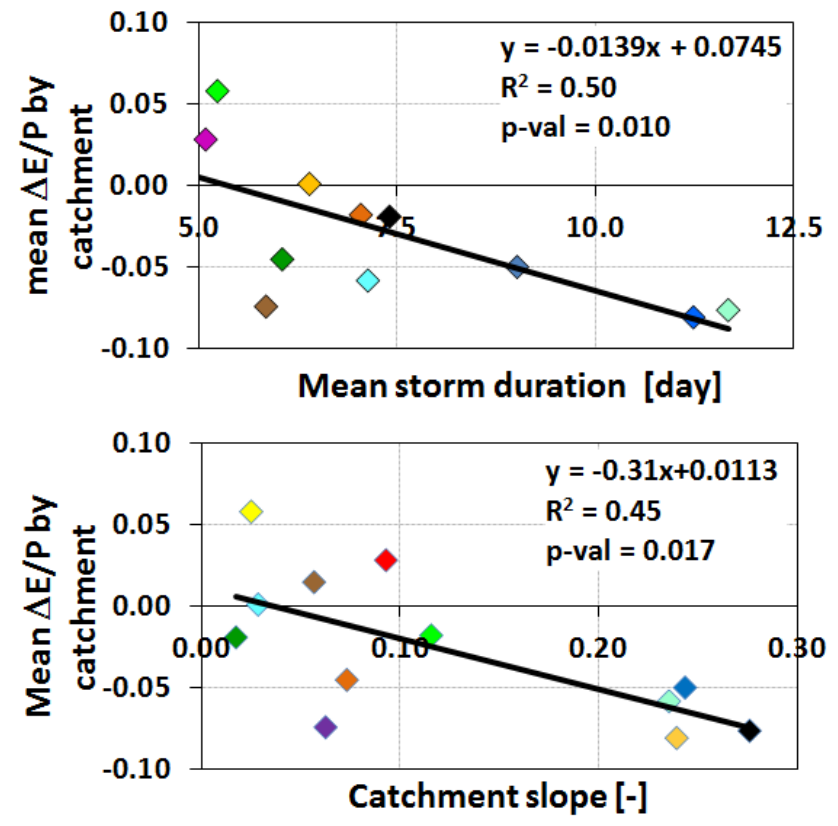

Fig. 5. Correlations between mean $\Delta E / P$ by catchment and mean storm duration (top; sample size: $12 ; p$ value: 0.01 ) and average catchment slope (bottom; sample size: $12 ; p$ value: 0.02 ).

stay longer in the aquifer, and since there is a connection between water storage in the perched aquifer and the root zone, plants have more time to take up that available water and hence will evaporate more. As can be seen from Eq. (2), this time scale combines landscape geomorphological information $\left(L, \alpha, a_{\mathrm{c}}, D\right)$ with hydrologic properties of the perched aquifer $\left(k_{\mathrm{h}}, f\right)$. The latter values are estimated during the calibration period and are thus directly affected by streamflow dynamics, whereas the former (except for $D$, which is included in the model calibration) are derived from digital elevation models. The linear regression in Fig. 6 explains $75 \%$ of the variability and suggests a strong coupling between climate characteristics and the time water can spend in subsurface storage before being released as baseflow.

We also analyzed several observed and derived catchment properties that possibly explain the observed trends per climate. Figure 7 shows a linear relationship between maximum leaf area index, estimated from $10 \mathrm{yr}$ of MODIS data (see Carrillo et al., 2011), and $\Delta(E / P)$ by climate. Again, a statistically significant relationship $(p<0.05)$ is observed. This time there is a positive correlation between these two variables, indicating that when the maximum leaf area index is high in a given catchment, its corresponding climate generates more evaporation when compared to Budyko's curve. When we compare $\Delta(E / P)$ with vegetation parameters estimated during the calibration process (in this case the vegetation root fraction and light use efficiency; Fig. 8), we can further explain the observed deviations from Budyko's predictions when analyzing our results by climate. $\Delta(E / P)$ seems 


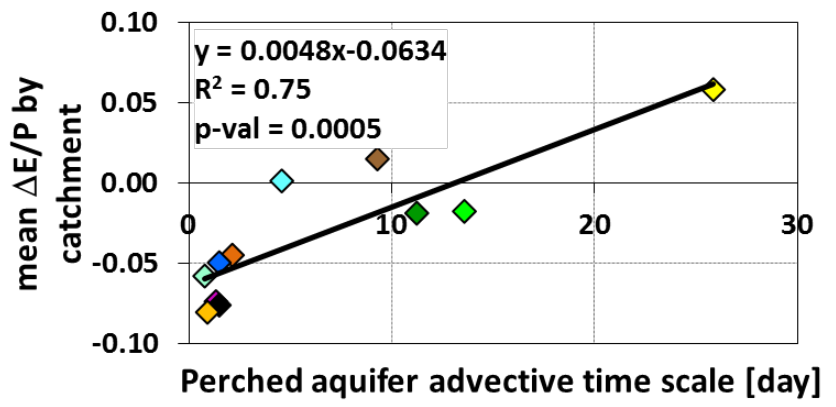

Fig. 6. Correlation between mean $\Delta E / P$ by catchment and perched aquifer advective time scale (sample size: $12 ; p$ value: 0.001 ).

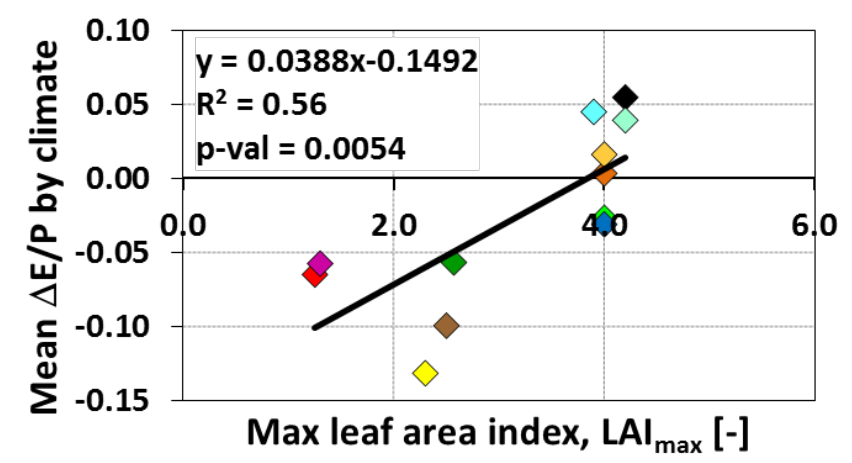

Fig. 7. Correlations between mean $\Delta E / P$ by climate and maximum value of the averaged leaf area index curve (sample size: 12; $p$ value: 0.005$)$.

to have a negative correlation with both these parameters and the fitted linear regressions explain $75 \%$ and $67 \%$ of the observed variability, respectively. The model vegetation parameters affect the catchment water balance through the following relationship (Teuling and Troch, 2005):

$t=\left(1-\omega_{\mathrm{WC}}\right) V_{\mathrm{RF}} \beta_{\mathrm{t}}\left(1-e^{-\mu \mathrm{LAI}}\right) T\left(r_{\mathrm{s}, \min }\right)$

where $t\left[\mathrm{~m} \mathrm{day}^{-1}\right]$ is transpiration rate, $\omega_{\mathrm{WC}}[-]$ is fraction of wet canopy, $V_{\mathrm{RF}}[-]$ is vegetation root fraction, $\beta_{\mathrm{t}}$ is the transpiration reduction factor, $\mu$ is light use efficiency, LAI is leaf area index, and $T\left(r_{\mathrm{s}, \min }\right)$ is the maximum transpiration rate corresponding to minimal stomatal resistance of the canopy. Climates that produce systematically more evaporation seem to correspond with catchment vegetation that is less efficient in its water use. Apparently, vegetation that is used to climates that produce more evaporation than Budyko's prediction seem to be less efficient in their use of water. This result hints at a co-evolution of the catchment's ecosystems and the corresponding climates, similar to the work of Gentine et al. (2012).
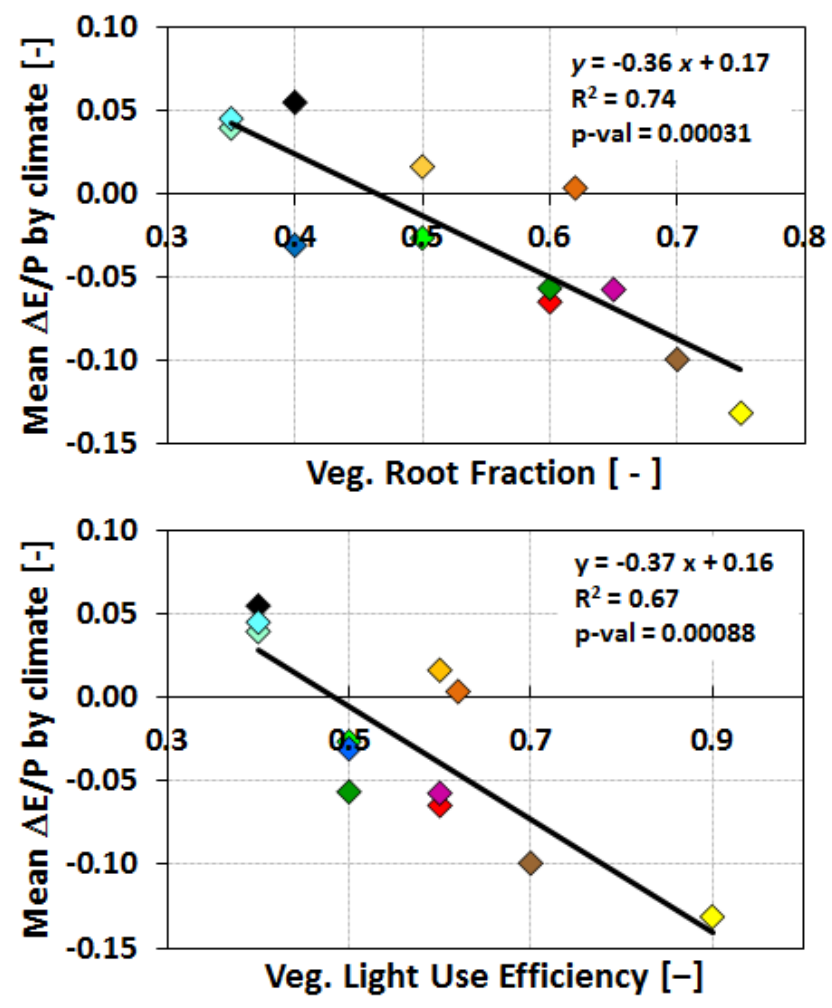

Fig. 8. Correlations between mean $\Delta E / P$ by climate and two model parameters, vegetation root fraction and vegetation light use efficiency (sample size: $12 ; p$ value: 0 and 0.001 , resp.).

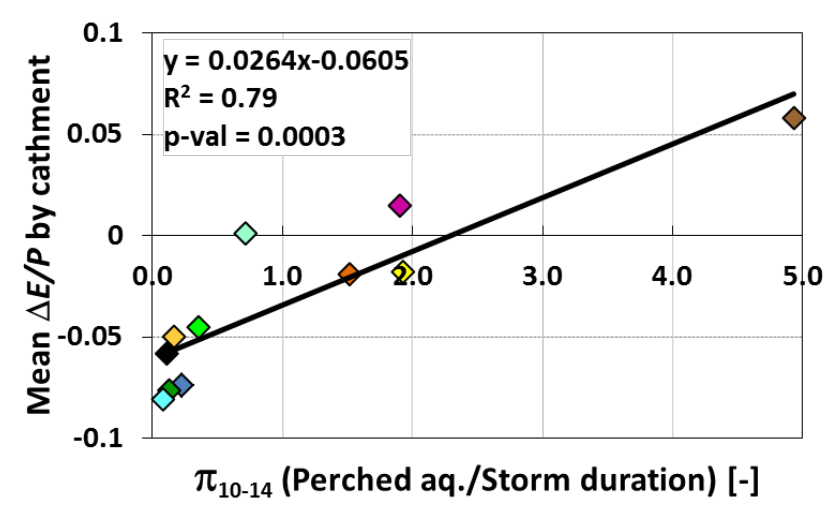

Fig. 9. Correlation between mean $\Delta E / P$ by catchment and the dimensionless number from the ratio of the perched aquifer and storm duration time scales (sample size: $12 ; p$ value: 0 ).

\section{Discussion and conclusion}

The motivation behind the present study was to try to understand the climatic and landscape controls on long-term hydrologic partitioning. Catchments demonstrate a surprisingly simple behavior across many different climate and landscape properties. This is best illustrated in the work of Budyko (1974) who hypothesized that the long-term hydrologic partitioning is driven to first degree by the aridity index, 
and is relatively immune to variations in intra-annual climate properties and catchment characteristics. This raises the question how different landscape properties interact with local climate dynamics to cause such a simple outcome. It also invites us to think whether this seemingly simple response is the result of some type of co-evolution between climate and catchment properties (more specifically the catchment's geomorphology, soils, topography and vegetation). Since true experimentation at the catchment scale is impossible, we have applied a space-for-time approach, in line with the methodology often adopted by Darwin (see Ghiselin, 1969, for an excellent discussion on Darwin's methods of research). This space-for-time approach was implemented with the aid of a process-based model that is capable of simulating hydrologic response across various climates and at different temporal scales. A total of 12 catchment scale model parameterizations were confronted with 12 different climates in an attempt to decouple climate drivers and landscape/model properties.

Our results indicate that there are strong relationships between how catchments partition incoming water and energy and their respective climates. Similarly, we see that the different climates impose specific hydrologic partitioning and that those tendencies are related to landscape properties and model parameters that affect water residence time and vegetation water use efficiencies. In contrast to what one would expect, when climates show a tendency to produce more evaporation compared to Budyko's hypothesis, their catchments have less efficient vegetation, and vice versa. This all indicates some level of co-evolution between climate and vegetation properties that are responsible for hydrological partitioning at the catchment scale.

To further illustrate this dependence, Fig. 9 shows a relationship between climate-driven hydrologic partitioning and a dimensionless number that is related to water residence time and storm duration. This dimensionless number combines geomorphologic properties of the landscape with hydrologic properties of the catchment aquifers and local climate dynamics. Again a strong significant relationship is revealed that explains $80 \%$ of the variance. When that dimensionless number is high (large residence time of water and short storm durations), the corresponding climate generates more evaporation than expected. This type of analysis sheds light on the interrelations between dominant drivers of catchment hydrology, and suggests that the observed relationships may be expressions of climate-vegetation-soil interactions at the catchment scale that systematically affect hydrologic partitioning. It is interesting to refer to Wang and $\mathrm{Wu}$ (2013) who report strong correlations between water balance partitioning and the perennial stream network, which also seems to suggest climate-landscape co-evolution that impact hydrologic response at the catchment scale. More research, including more catchments and possibly other model parameterizations, is needed to provide further evidence for these observations.
Recent opinion papers in hydrology and ecology (Harte, 2002; Sivapalan, 2005; McDonnell et al., 2007) have suggested that great progress can be expected if the Earth sciences reconcile the Newtonian with the Darwinian worldview. Several recent studies have attempted to apply Darwinian methodology to catchment studies (Jothityangkoon and Sivapalan, 2009), but an overarching theory of catchment response based on the idea of catchment co-evolution has yet to emerge. We refer to Harman and Troch (2013) for an in-depth discussion on this issue. Our results here indicate that there exist strong connections between hydrologic partitioning and several soil-vegetation-climate processes at the catchment scale. Unraveling the interactions and feedbacks that result in these connections will ultimately allow us to inform catchment-scale Earth process models in ways that account for these existing interactions between climate, soils and vegetation.

Acknowledgements. Support for this project was provided by the National Science Foundation under project EAR-0635998 "Understanding the Hydrologic Implications of Landscape Structure and Climate - Towards a Unifying Framework of Watershed Similarity". Support was also provide by the National Science Foundation under project EAR-0724958 "CZO: Transformative Behavior of Water, Energy and Carbon in the Critical Zone: An Observatory to Quantify Linkages among Ecohydrology, Biogeochemistry, and Landscape Evolution".

Edited by: L. Samaniego

\section{References}

Budyko, M. I.: Climate and Life, Academic Press, New York, 508 pp., 1974.

Carrillo, G., Troch, P. A., Sivapalan, M., Wagener, T., Harman, C., and Sawicz, K.: Catchment classification: hydrological analysis of catchment behavior through process-based modeling along a climate gradient, Hydrol. Earth Syst. Sci., 15, 3411-3430, doi:10.5194/hess-15-3411-2011, 2011.

Duan, Q., Schaake, J., Andreassian, V., Franks, S., Gupta, H. V., Gusev, Y. M., Habets, F., Hall, A., Hay, L., Hogue, T. S., Huang, M., Leavesley, G., Liang, X., Nasonova, O. N., Noilhan, J., Oudin, L., Sorooshian, S., Wagener, T., and Wood, E. F.: Model Parameter Estimation Experiment (MOPEX): Overview and Summary of the Second and Third Workshop Results, J. Hydrol., 320, 3-17, 2006.

Gentine, P., D’Odorico, P., Lintner, B., Sivandran, G., and Salvucci, G.: Interdependence of climate, soil and vegetation as constrained by the Budyko curve, Geophys. Res. Lett., 39, L19404, doi:10.1029/2012GL053492, 2012.

Gerrits, A. M. J., Savenije, H. H. G., Veling, E. J. M., and Pfister, L.: Analytical derivation of the Budyko curvebased on rainfall characteristics and a simple evaporation model, Water Resour. Res., 45, W04403, doi:10.1029/2008WR007308, 2009.

Ghiselin, M. T.: The Triumph of the Darwinian Method, Dover Publications, 1969. 
Harman, C. and Troch, P. A.: Darwinian hydrology: can the methodology Charles Darwin pioneered help hydrologic science?, Hydrol. Earth Syst. Sci. Discuss., 10, 6407-6444, doi:10.5194/hessd-10-6407-2013, 2013.

Harte, J.: Toward a synthesis of the Newtonian and Darwinian worldviews, Phys. Today, 30 October, 29-34, 2002.

Huxman, T. E., Smith, M. D., Fay, P. A., Knapp, A. K., Shaw, M. R., Loik, M. E., Smith, S. D., Tissue, D. T., Zak, J. C., Weltzin, J. F., Pockman, W. T., Sala, O. E., Haddad, B. M., Harte, J., Koch, G. W., Schwinning, S., Small, E. E., and Williams, D. G.: Convergence across biomes to a common rain-use efficiency, Nature, 429, 651-654, 2004.

Jenny, H.: Factors of Soil Formation, McGraw-Hill, New York, 1941.

Jothityangkoon, C. and Sivapalan, M.: Framework for exploration of climatic and landscape controls on catchment water balance, with emphasis on inter-annual variability, J. Hydrol., 371, 154168, doi:10.1016/j.jhydrol.2009.03.030, 2009.

McDonnell, J. J., Sivapalan, M., Vaché, K., Dunn, S., Grant, G., Haggerty, R., Hinz, C., Hooper, R., Kirchner, J., Roderick, M. L., Selker, J., and Weiler, M.: Moving beyond heterogeneity and process complexity: A new vision for watershed hydrology, Water Resour. Res., 43, W07301, doi:10.1029/2006WR005467, 2007.

Milly, P. C. D.: Climate, soil water storage, and the average annual water balance, Water Resour. Res., 30, 2143-2156, 1994.

Potter, N. J., Zhang, L., Milly, P. C. D., McMahon, T. A., and Jakeman, A. J.: Effects of rainfall seasonality and soil moisture capacity on mean annual water balance for Australian catchments, Water Resour. Res., 41, W06007, doi:10.1029/2004WR003697, 2005.

Schymanski, S. J., Sivapalan, M., Roderick, M. L., Beringer, J., and Hutley, L. B.: An optimality-based model of the coupled soil moisture and root dynamics, Hydrol. Earth Syst. Sci., 12, 913932, doi:10.5194/hess-12-913-2008, 2008.
Silberstein, R. P., Held, A., Hatton, T. J., Viney, N. R., and Sivapalan M.: Energy balance of a natural jarrah (Eucalyptus marginata) forest in Western Australia. Measurements in spring and summer, Agr. Forest Meteorol., 109, 79-104, 2001.

Sivapalan, M.: Patterns, process and function: Elements of a unified theory of hydrology at the catchment scale, in: Encyclopedia of Hydrological Sciences, John Wiley and Sons, 2005.

Troch, P. A., Martinez, G. F., Pauwels, V. R. N., Durcik, M., Sivapalan, M., Harman, C., Brooks, P. D., Gupta, H., and Huxman, T. E.: Climate and vegetation water use efficiency at catchment scales, Hydrol. Process., 23, 2409-2414, 2009.

Troch, P. A., Paniconi, C., and van Loon, E. E.: The hillslopestorage Boussinesq model for subsurface flow and variable source areas along complex hillslopes: 1. Formulation and characteristic response, Water Resour. Res., 39, 1316, doi:10.1029/2002WR001728, 2003.

Teuling, A. and Troch, P. A.: Improved understanding of soil moisture variability dynamics, Geophys. Res. Lett., 32, L05404, doi:10.1029/2004GL021935, 2005.

Whittaker, R. H. and Niering, W. A.: Vegetation of the Santa Catalina Mountains, I: Ecological classification and distribution of species, J. Ariz. Acad. Sci., 3, 9-34, 1964.

Wolock, D. M. and McCabe, G. J.: Explaining spatial variability in mean annual runoff in the conterminous United States, Clim. Res., 11, 149-159, 1999.

Walsh, R. P. D. and Lawler, D. M.: Rainfall seasonality spatial patterns and change through time, Weather, 36, 201-208, 1981.

Wang, D. and Wu, L.: Similarity of climate control on base flow and perennial stream density in the Budyko framework, Hydrol Earth Syst. Sci., 17, 315-324, doi:10.5194/hess-17-315-2013, 2013. 